\title{
RADAR BACKSCATTERING MEASUREMENT OF BARE SOIL AND VEGETATION COVERED SOIL USING X-BAND AND FULL POLARIZATION
}

\author{
B. Goswami ${ }^{\text {a, }}$, M. Kalita ${ }^{\text {a }}$ \\ a Dept. of Electrical and Electronics Engineering, Assam Don Bosco University, Airport Road, Guwahati, India- 781017 - \\ bikramjit.goswami@dbuniversity.ac.in \\ ${ }^{\mathrm{b}}$ Dept. of Civil Engineering, Assam Don Bosco University, Airport Road, Guwahati, India- 781017 - \\ principal.dbcet@dbuniversity.ac.in
}

KEY WORDS: Land Cover, Active Remote Sensing, Microwave Remote Sensing, Radar backscatter, Scatterometer, Look angle, Polarization.

\begin{abstract}
:
The objective of the study is to measure backscattered power of bare soil and vegetation covered soil using X-band scatterometer system with full polarization and various angles during monsoon season and relate backscattered power to the density of vegetation over soil. The measurement was conducted at an experimental field located in the campus of Assam Engineering College, Guwahati, India. The soil sample consists of Silt and Clay in higher proportions as compared to Sand. The scatterometer system consists of dual-polarimetric square horn antennas, Power meter, Klystron, coaxial cables, isolator and waveguide detector. The polarization of the horn antennas as well as the look angle can be changed in the set-up. The backscattering coefficients were calculated by applying a radar equation for the measured values at incident angles between $30^{\circ}$ and $60^{\circ}$ for full polarization (HH, $\mathrm{VV}, \mathrm{HV}, \mathrm{VH}$ ), respectively, and compared with vegetation cover over soil for each scatterometer measurement simultaneously. The $\mathrm{VH}$ polarization and $60^{\circ}$ look angle are found to be the most suitable combination of configuration of an X-band scatterometer for distinguishing the land cover targets such as bare soil and vegetation covered soil. From the analysis of the results, polarimetric scatterometer data appear to be promising to distinguish the land cover types such as bare soil and soil completely covered by vegetation. The results of this study will help the scientists working in the field of active microwave remote sensing.
\end{abstract}

\section{INTRODUCTION}

India is an agriculture rich country. In spite of the dependence of the country on agriculture sector to great extent, there have been very few attempts to monitor agriculture and vegetation coverage over the soil with microwave instrument from both space and ground platforms. Microwave radar has got the very important property of being able to penetrate through cloud, fog, haze etc. This property makes microwaves useful for remote sensing of the areas in the tropical regions.

In the tropical regions, the growth of vegetation including grass is significantly higher during monsoon season, when the cloud cover is a common phenomenon. However, the planning of land-use using the data collected from remote sensing satellites is very often done. Hence, in tropical regions microwave remote sensing is the only possible form of remote sensing from the satellites during the monsoon season, as optical sensors cannot practically see the ground through the cloud cover. For the interest of developing the right sensor characteristics of the microwave remote sensing systems, the studies related to active microwave sensors like the scatterometers are done.

$\mathrm{X}$-band is found to be useful in remote sensing of vegetation, as reported in many literatures. In (Kim, 2000) it is explained that, as the vegetation grows over soil, the backscattering coefficients increase only until the leaves become large and dense enough. After that, the random scattering and attenuation due to leaves block the contributions from the stems. This effect seems to be much stronger in X-band than at longer wavelength bands. In another literature (Mattia, 2003) the rice grain weight was correlated with backscattering coefficients with X-band in VV polarization at a larger incidence angle. $\mathrm{X}$-band was found to be sensitive to grain maturity at near harvesting season. X-band scatterometers have also been used to estimate rice growth parameters (Kim, 2008), by correlating with backscattering coefficients at VV polarization and $45^{\circ}$ look angle. As described in (Kwon, 2011), the polarimetric radar backscatters of a soya bean field were measured using a ground based X-band polarimetric scatterometer. The soil moisture of the soya bean field was also retrieved from the surface scattering term using the empirical surface scattering model.

In the present study, we have examined the differences in behavior of radar backscatter from bare soil and vegetation covered soil, with respect to the percentage coverage of soil by vegetation, at X-band frequencies and full polarization with angular response.

\section{MATERIAL AND METHOD}

The test site was located at Assam Engineering College campus (Latitude $26.16 \mathrm{~N}$, Longitude $91.72 \mathrm{E}$ ), situated at Guwahati, India. The size of the field was about $200 \mathrm{~m}^{2}$. Table 1 shows the scatterometer system specification. The system mainly composed of dual-polarimetric square horn antennas, Klystron, Isolator, Waveguide detector, coaxial cables and Power meter. 


\begin{tabular}{|l|c|}
\hline Specification & $\mathrm{X}$ - band scatterometer value \\
\hline Center frequency & $9.48 \mathrm{GHz}$ \\
Bandwidth & $1 \mathrm{GHz}$ \\
Antenna type & Dual polarimetric horn \\
Antenna gain & $22.1 \mathrm{~dB}$ \\
Polarization & $\mathrm{HH}, \mathrm{VV}, \mathrm{HV}, \mathrm{VH}$ \\
Incident angle & $30^{\circ} \sim 60^{\circ}$ \\
Platform height & $2 \mathrm{~m}$ \\
\hline
\end{tabular}

Table 1. Specification of the Scatterometer System

The X-band scatterometer provides a time domain radar return from a target as a fully polarimetric $(\mathrm{HH}, \mathrm{HV}, \mathrm{VH}, \mathrm{VV})$ amplitude and phase data. Radar backscattering measurements were taken for the period of May-July 2014. The received power is related to various parameters of the scatterometer as well as the target material by the radar equation (Calla, 2009), as shown in the expression (1).

$$
P_{r}=\frac{P_{t} G_{t} G_{r} \lambda^{2} \sigma}{(4 \pi)^{2} R^{4}}
$$

where, $P_{t}$ is the transmit power and $P_{r}$ is the received power, $G_{t}$ and $G_{r}$ are the gains of transmitting and receiving antennas in the direction of the target, $\lambda$ is the wavelength, $R$ is the distance between the antenna and the target material, and $\sigma$ is the radar cross section of the target.

The received power therefore depends on the radar cross section of the target, which would be different for different types of the soil cover.

\section{RESULTS AND DISCUSSION}

Radar return from bare soil and vegetation covered soil have been recorded with various polarization $(\mathrm{HH}, \mathrm{HV}, \mathrm{VH}$ and VV) and look angle $\left(30^{\circ} \sim 60^{\circ}\right)$. The received power in each case in $\mathrm{dB}$ are plotted as shown in the Fig. 1-8. The readings taken are for the days before rain (dry season) and after rain (monsoon season). The variations in backscattered power due to polarization and look angle variations are plotted for determining the most suitable configuration of a scatterometer for vegetation cover detection. The readings taken are for bare soil, soil partially covered with vegetation (nearly $50 \%$ of the area being covered by vegetation) and soil fully covered by vegetation (approximately 100\% of the area of interest being covered). Moreover, different sets of readings are taken for the same places and same soil cover types before rain and after rain, within the same period of time of measurement. In the Fig. 1-8 the green curves show the received power in $\mathrm{dB}$ versus the type of soil cover for $30^{\circ}$ look angle of the scatterometer. Similarly the blue and red curves show the received power levels at $60^{\circ}$ and $45^{\circ}$ look angles of the scatterometer respectively.

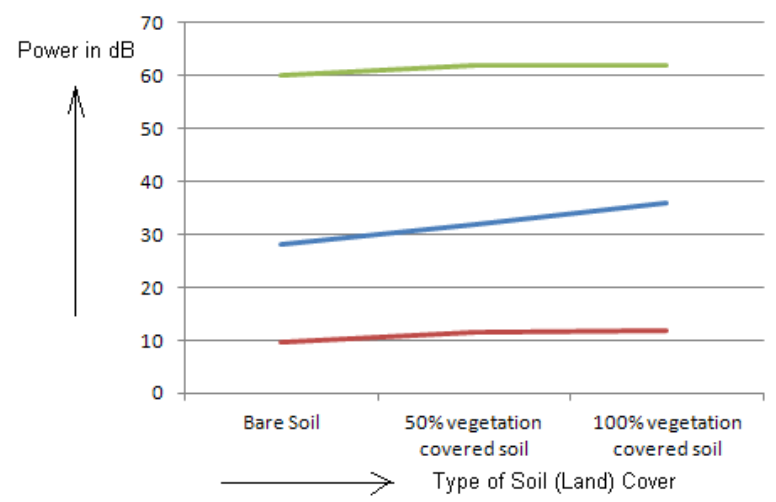

Figure 1. Received power variations for various land cover types during dry weather conditions for $\mathrm{HH}$ polarization

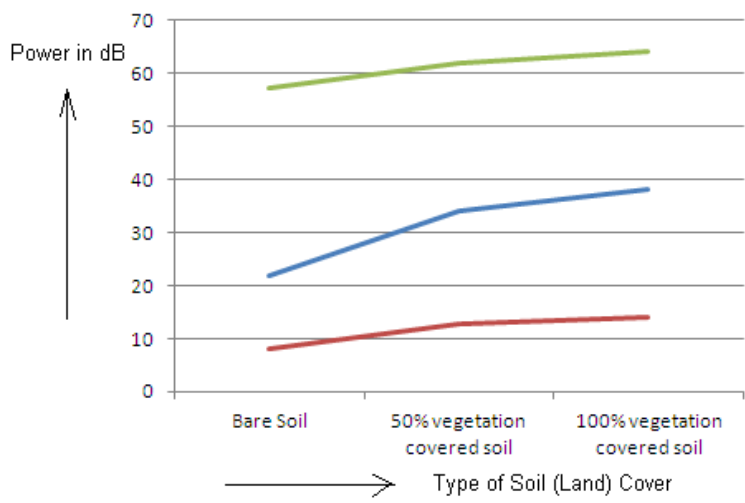

Figure 2. Received power variations for various land cover types after rain, during moist weather conditions for $\mathrm{HH}$ polarization

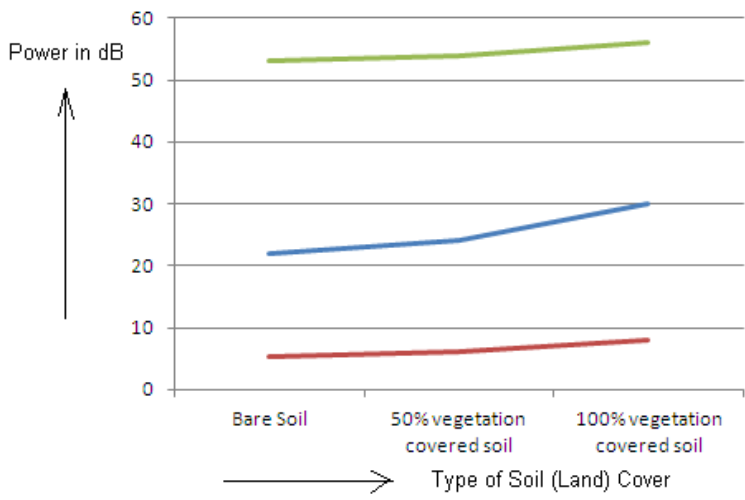

Figure 3. Received power variations for various land cover types during dry weather conditions for VV polarization 


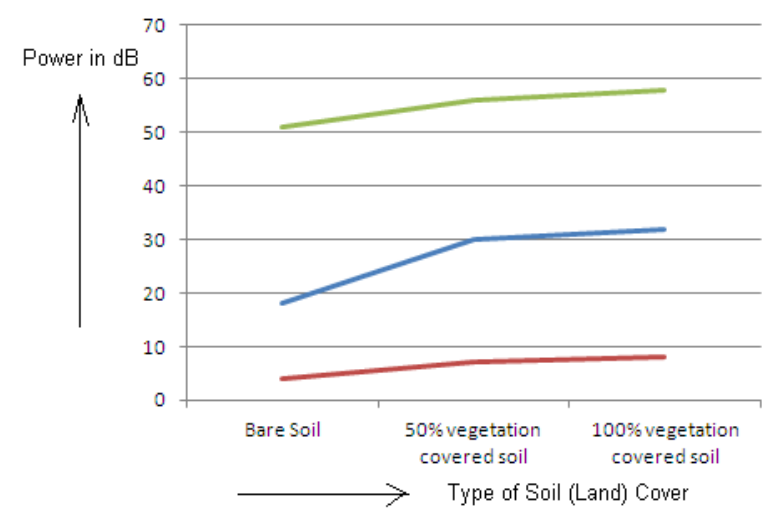

Figure 4. Received power variations for various land cover types after rain, during moist weather conditions for VV polarization

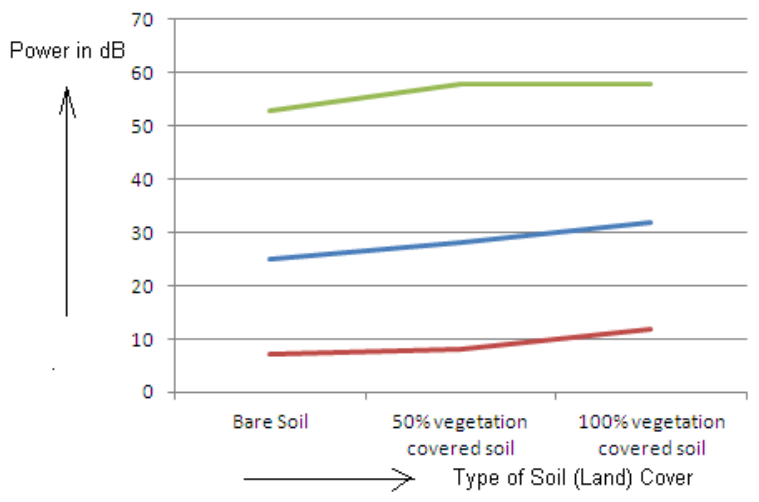

Figure 5. Received power variations for various land cover types during dry weather conditions for HV polarization

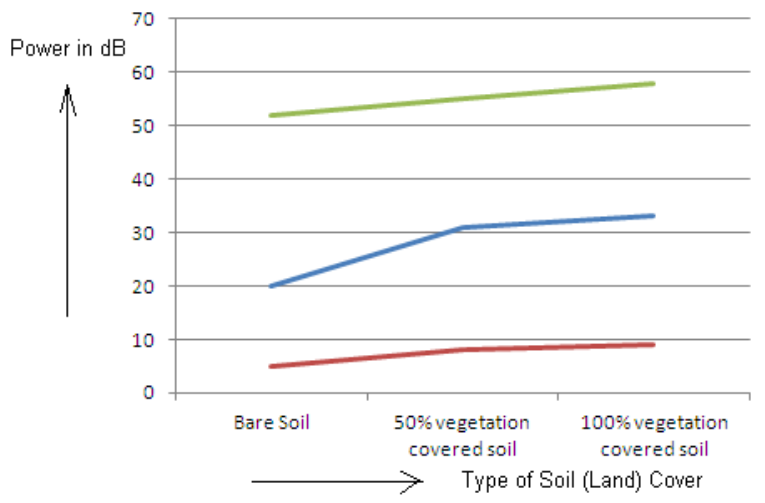

Figure 6. Received power variations for various land cover types after rain, during moist weather conditions for HV polarization

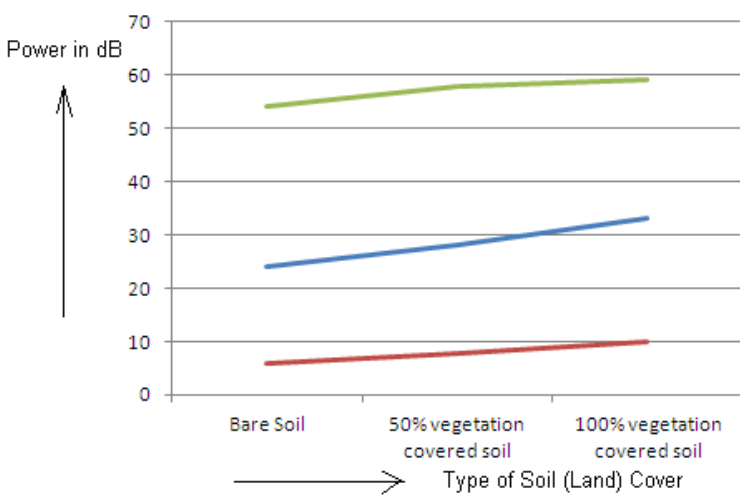

Figure 7. Received power variations for various land cover types during dry weather conditions for $\mathrm{VH}$ polarization

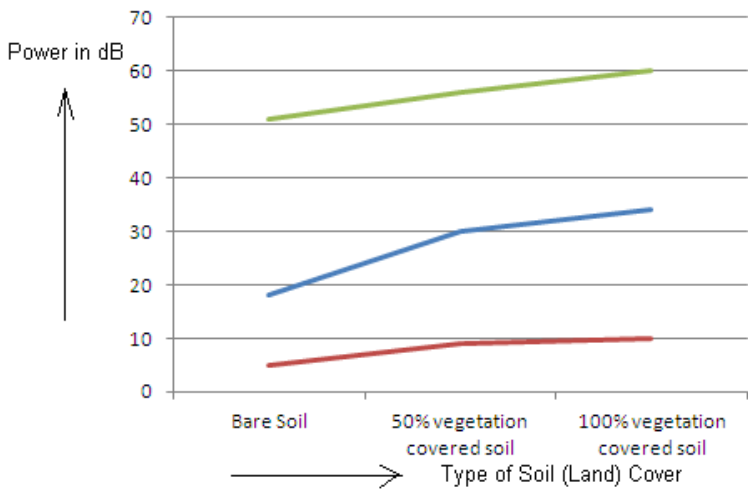

Figure 8. Received power variations for various land cover types after rain, during moist weather conditions for $\mathrm{VH}$ polarization

The variations in the received power levels due to change in soil cover types are noted and from the graphs it is seen that the variations are more significant in some combinations of polarization and look angle as compared to the rest. From the graphs it is observed that $60^{\circ}$ look angle with the $\mathrm{VH}$ polarization, i.e., the transmitter at Vertical polarization and the receiver at Horizontal polarization gives the best difference in received power levels $(9 \mathrm{~dB})$ for bare soil and soil completely covered by vegetation during the dry soil conditions (before rain). However both $\mathrm{HH}$ and $\mathrm{VH}$ polarization when used with $60^{\circ}$ look angle is found to be showing the best difference in received power levels $(16 \mathrm{~dB})$ with the variations in the target type, i.e., bare soil and soil covered by vegetation during the moist soil conditions (after rain). To distinguish between bare soil and soil partially covered by vegetation (approximately 50\% of the area of soil covered by vegetation), the $\mathrm{HH}$ and $\mathrm{VH}$ polarizations with $60^{\circ}$ look angle are found to be most suitable (with $4 \mathrm{~dB}$ difference in received power) during dry soil conditions. Similarly, for the moist soil conditions, the $\mathrm{HH}, \mathrm{VV}$ and $\mathrm{VH}$ polarizations with $60^{\circ}$ look angle are found to be the best configuration of the X-band scatterometer (with $12 \mathrm{~dB}$ difference in received power) to distinguish between bare soil and soil partially covered by vegetation.

For all types of soil cover and all types of weather as well as soil moisture states, the $\mathrm{VH}$ polarization (transmitter antenna in vertical polarization mode and receiver antenna in horizontal polarization mode) with $60^{\circ}$ look angle is found to be the best combination of configuration for an X-band scatterometer for distinguishing the land cover types, viz., bare soil and vegetation covered soil. 


\section{CONCLUSIONS}

Backscattered power of bare soil and soil covered by vegetation were investigated with a ground-based scatterometer operating at X-band. The variations in received power with the changes in look angle and polarization of the scatterometer were studied. The various combinations of polarizations and look angles reveal the suitability of certain combinations over others in identifying certain land cover types. The $\mathrm{VH}$ polarization and $60^{\circ}$ look angle are found to be the most suitable combination of configuration of an X-band scatterometer for distinguishing the land cover targets such as bare soil and vegetation covered soil. From the analysis of the results, polarimetric scatterometer data appears positive to distinguish the land cover types such as bare soil, soil covered partially by vegetation and soil completely covered by vegetation. The results of this study will help the scientists working in the field of active microwave remote sensing by providing information directly as measured physically in the field. This in-situ measurement information will be useful in deciding the configuration of the active sensors on board the microwave remote sensing satellites.

\section{ACKNOWLEDGEMENTS}

Authors would like to thank the department of Electronics and Telecommunication Engineering of Assam Engineering College (Guwahati, India) for allowing and facilitating the measurements.

\section{REFERENCES}

Kim, S.B., Kim, B.W., Kong, Y.K. Kong, and Kim, Y.S., 2000. Radar Backscattering Measurements of Rice Crop Using $\mathrm{X}$-Band Scatterometer. IEEE Transactions on Geoscience and Remote Sensing, vol. 38, no. 3, pp. 1467-1471.

Mattia F., Toan T.L., Picard G., Posa F.I., Alessio A.D., Notarnicola C., Gatti A.M., Rinaldi M., Satalino G., and Pasquariello G., 2003. Multitemporal C-Band Radar Measurements on Wheat Field. IEEE Transactions on Geoscience and Remote Sensing, vol. 41, no. 7, pp. 1551-1560.

Kim Y.H., Hong S.Y., and Lee H., 2008. Radar Backscattering Measurement of a Paddy Rice Field using Multi-frequency (L,C and X) and Full-polarization. Proceedings of IGARSS 2008, vol. 4, pp. 553-556.

Kwon S.G., Hwang J.H., and Oh Y., 2011. Soil Moisture Inversion from X-band SAR and Scatterometer Data of Vegetation Fields. Proceedings of IGARSS 2011, pp. 31403143.

Ulaby F.T., 1990. Radar Polarimetry for Geoscience Applications. Artech House Inc.

Calla O.P.N., 2009. Microwave Remote Sensing. DRDO monographs/special publications series.

Woodhouse I.H., 2006. Introduction to Microwave Remote Sensing. CRC Press, Taylor and Francis Group. 